\title{
Síndrome da meningite asséptica por enterovírus e Leptospira sp em crianças de Salvador, Bahia
}

\author{
Aseptic meningitis syndrome due to enterovirus and \\ Leptospira sp in children of Salvador, Bahia
Hagamenon R. Silva', Gustavo Mustafa Tanajura', José Tavares-Neto², Maria de Lourdes C. Gomes ${ }^{3}$, Alexandre da Costa Linhares ${ }^{3}$, Pedro F C Vasconcelos ${ }^{4}$, Albert Icksang Ko ${ }^{5}$

\begin{abstract}
Resumo Objetivando verificar a freqüência de enterovírus (EV), leptospiras e arbovírus como agentes causais da síndrome da meningite asséptica (SMA), em períodos não-epidêmicos, e comparar os pacientes com e sem diagnóstico etiológico determinado, foram selecionados 112 pacientes de idade entre 3 meses e 15 anos, com suspeita clínica de SMA, referenciados para Hospital Couto Maia, especializado em Doenças Infecciosas e Parasitárias (Salvador, Bahia), Em 44,6\% $(n=50)$ a etiologia foi determinada: enterovírus em 37,7\% ( $n=42)$ dos casos, pelo teste de PCR Amplicor, por cultura do líquor e/ou de fezes; a Leptospira $s p$. em 7,1\% (n=8), pelo método da micro-aglutinação, e nenhum caso de arbovírus foi detectado (inibição da hemaglutinação passiva). Entre os 14 enterovírus dos 22 isolados, foram identificados seis diferentes sorotipos, sendo o Echovirus-4 predominante (27,2\%; 6/22) entre outros (Coxsackie B2, B3, B6 e B9; EV 71). Conclui-se que, os enterovírus foram os agentes mais freqüentes, e que a leptospirose deve ser lembrada no diagnóstico diferencial da SMA. Uma vez que as características clínicas e liquóricas dos pacientes dos grupos com e sem determinação do agente etiológico foram semelhantes, pode-se supor que o diagnóstico presuntivo de SMA é de provável etiologia viral ou pela leptospira.
\end{abstract}

Palavras-chaves: Síndrome da meningite asséptica. Enterovírus. Leptospira. Criança.

Abstract For the purpose of identifying the frequency that enterovirus, leptospires, arbovirus cause aseptic meningitis syndrome (AMS) during non-epidemic periods and comparing patients with and without laboratory evidence for an etiologic agent, 112 patients were selected aged between 3 months and 15 years and a clinical suspicion of AMS and were referred to Couto Maia Hospital, the Infectious and Parasitic Disease Reference Center for Salvador, Bahia. In 44.6\% ( $n=50)$, the etiologic agent for the diagnosis was laboratory-confirmed: enterovirus was identified in $37.7 \%$ ( $n=42$ ) of the cases by the PCR Amplicor diagnostic kit, cerebrospinal fluid or fecal culture isolation; Leptospira sp. in $7.12 \%(n=8)$ by the microagglutination test; and arbovirus in non of the cases by inhibition of passive hemagglutination. In 14 of the 22 enteroviral isolates that were evaluated, 6 different serotypes were identified with Echovirus-4 being the major serotype (27.2\%; 6/22) among all found (Coxsackie B2, B3, B6 and B9; Enterovirus 71). In conclusion, enteroviruses were the most frequent etiologic agent of AMS and that leptospirosis should be included in the differential diagnosis. In addition, patients with and without laboratory-confirmed identification of the etiologic agent had similar demographic and clinical characteristics and cerebrospinal fluid findings $(p>0.05)$, therefore suggesting that patients without a confirmed diagnosis had enteroviral or leptospiral etiologies.

Key-words: Aseptic meningitis syndrome. Enterovirus. Leptospira. Children.

\footnotetext{
1. Centro de Estudos de Infectologia Pediátrica do Hospital Couto Maia da Secretaria de Saúde do Estado da Bahia e Departamento de Pediatria da Faculdade de Medicina da Universidade. Federal da Bahia. 2. Disciplina de Doenças Infecciosas e Parasitárias da Faculdade de Medicina da Universidade. Federal da Bahia. 3. Serviço de Virologia Geral do Instituto Evandro Chagas de Belém, Pará da Fundação Nacional de Saúde. 4 . Serviço de Arbovírus do Instituto Evandro Chagas. 5. Centro de Pesquisas Gonçalo Muniz da Fundação Osvaldo Cruz, Salvador Bahia e da Divisão de Medicina Internacional de Doenças Infecciosas da Faculdade de Medicina da Universidade de Cornell, New York, USA.

Endereço para correspondência: Dr. Hagamenon R. da Silva. Rua Humberto de Campos 159/301. Graça 40150-130 Salvador-BA.

Tel. 71 247-5559, Fax: 71 332-6721.

E-mail: hagars@ufba.br

Recebido para publicação em 28/3/2001.
} 
Meyer et $\mathrm{al}^{13}$ em 1960, estudando as infecções do sistema nervoso central (SNC), encontraram 60,3\% (430/ 713) dos pacientes com síndrome da meningite asséptica (SMA) e em 70,9\% (305/430) a etiologia foi determinada: $41,9 \%$ ( $n=128)$ dos casos foram por enterovírus não-pólio; $12,4 \%(\mathrm{n}=38)$ pelo poliovírus; $22,2 \%(\mathrm{n}=68)$ pelo vírus da parotidite; $12,4 \%(n=38)$ pelo vírus da coriomeningite linfocitária benigna (VCL); 5,5\% $(\mathrm{n}=17)$ por leptospira; $1,9 \%(n=6)$ por Herpes simples; $0,9 \%(n=3)$ por arbovírus; $0,03 \%(n=1)$ pelo Mycobacterium tuberculosis; e 1,9\% $(n=6)$ por outros agentes.

Nos anos 90, ao se utilizar métodos diagnósticos mais sensíveis ${ }^{6} 8182425$, reforçou-se relevância de agentes virais como causa da SMA. Os enterovírus apareceram numa freqüência entre $24,5 \%$ a $97 \%$ dos casos. Porém, outros agentes microbianos (bactérias e fungos), focos parameningeos, abscessos cerebrais, alguns tumores do encéfalo, bem como certos agentes físicos e químicos, podem ter expressão clínica e liquórica semelhante a observada na SMA ${ }^{15}$.

No Brasil, na década de 70 , Lopes et al ${ }^{11}$ descreveram em São Paulo um surto de encefalite com 420 casos e 18 óbitos, sendo identificado na histopatologia do SNC um novo arbovírus (Rocio), do grupo dos flavivírus. Posteriormente, Pinheiro et $\mathrm{al}^{16}$, em epidemia de meningite na Amazônia, identificaram o Bunyavirus Oropouche. Em 1985, Silva et al ${ }^{20}$ descreveram em Santa Catarina os aspectos clínico-epidemiológicos de 77 pacientes, de idades inferiores a 14 anos, com características de SMA e que os autores aventaram a possibilidade da etiologia ter sido por enterovírus. No fim da década de 80, Takimoto et al ${ }^{23}$, relataram no Estado de São Paulo, também outro surto de SMA em 138 pacientes de idades entre 4 meses e 57 anos, e de 53 amostras de líquor cultivadas, em 35 amostras foi isolado um vírusRNA, mas sem identificação do grupo.

Contudo no Brasil, não há referência de trabalho de identificação de agentes causais da SMA, em períodos não-epidêmicos. Daí porque este estudo tem como objetivos: o de estimar a freqüência de enterovírus, leptospiras e arbovírus como agentes etiológicos da SMA, em crianças e adolescentes com suspeita clínica de SMA e de verificar as características do líquor, os dados demográficos e as manifestações clínicas à admissão hospitalar mais freqüentes, bem como a evolução clínica destes pacientes.

\section{MATERIAL E MÉTODOS}

Pacientes e espécimes biológicos. Este estudo transversal, foi realizado no Hospital Couto Maia (HCMaia), especializado em doenças infectoparasitárias da Secretaria de Saúde do Estado da Bahia, da cidade do Salvador (Brasil). As crianças e adolescentes, incluídos no estudo, tinham as seguintes características: idades entre 3 meses e 15 anos; de ambos os sexos; líquor de aspecto límpido ou levemente opalescente, com $\geq 10$ até $\leq 2000$ células $/ \mathrm{m}^{3}$; proteína $\leq 150 \mathrm{mg} / \mathrm{dl}$; glicose $\geq 40 \mathrm{mg} \%$; exames microbiológicos negativos (Gram, tinta da China, culturas para bactéria e fungos); e concordância dos pais ou responsáveis legais, através da assinatura do termo de consentimento aprovado pela Comissão de Ética do HCMaia (processo 01/97). Os critérios de exclusão foram: pacientes com meningite bacteriana ou fúngica, meningite recidivante, meningite pós-caxumba diagnosticada por história recente ou concomitante de parotidite epidêmica, pacientes em coma e causas não-infecciosas de SMA.

O líquor, coletado na admissão, foi separado em duas alíquotas: uma de 2 a $3 \mathrm{ml}$ encaminhada de imediato para o Laboratório do Hospital para realização do exame do líquor (citologia, bioquímica, Gram, tinta da China e culturas para bactéria e fungos ) e a outra alíquota de $1 \mathrm{ml}$ estocada de imediato (até dois minutos após coleta ) em botijão com nitrogênio líquido. De cada paciente, também foi coletada uma amostra de fezes (nos cinco primeiros dias de internação) e duas amostras de sangue venoso, sendo uma no primeiro dia do atendimento e a segunda após 20 dias da admissão hospitalar (no ambulatório ou em visita domiciliar). As amostras séricas e de fezes foram estocadas $-20^{\circ} \mathrm{C}$. Posteriormente, lotes de 15 a 20 amostras (líquor, espécimes fecais e amostras séricas) eram acondicionados e enviados para o Instituto Evandro Chagas (IEC) da Fundação Nacional de Saúde (Belém, Pará) para investigação dos agentes virais. Outras alíquotas das amostras séricas também foram encaminhadas para o Centro de Pesquisas Gonçalo Moniz, CPqGM (FIOCRUZ, Salvador-Bahia) para investigação de Leptospira sp.

Métodos diagnósticos (Enterovírus e Arbovírus). As amostras de fezes e do líquor foram cultivadas para enterovírus no Laboratório de Virologia Geral do IEC, com identificação do sorotipo das amostras positivas e em $0,1 \mathrm{ml}$ da alíquota do líquor foi realizada, também, 0 Amplicor teste $P C R$ do Laboratório Roche Farmacêutica (PCR-EV) ${ }^{24}$. O Amplicor teste PCR, para o diagnóstico de enterovírus no líquor, foi realizado de acordo as instruções do fabricante $\left(\right.$ Roche $\left.^{R}\right)$. A detecção de antígenos de enterovírus foi realizada colorimetricamente em placas microtituladas, sensibilizadas com sondas específicas de oligonucleotído para enterovírus ${ }^{25}$. Este teste é capaz de identificar a maioria dos diferentes sorotipos de enterovírus, exceto os Echovirus E22 e E23 pois têm as seqüências diferentes dos componentes do $\mathrm{RNA}^{25}$. As amostras com leituras à $A_{450}{ }^{3} 0,35 \mathrm{U}$ foram consideradas positivas. A leitura foi considerada válida quando todos os controles negativos, em triplicatas, apresentaram $<0,25 \mathrm{~A}_{450} \mathrm{U}$ ou quando pelo menos dois dos controles positivos tiveram $>2,0 \mathrm{~A}_{450} \mathrm{U}$.

A pesquisa de anticorpos anti-arbovírus foi realizada pelo teste de inibição da hemaglutinação, nos soros pareados no Laboratório de Arbovírus do IEC, pela 
técnica de Clarke \& Casals $^{2}$ modificada por Shope ${ }^{19}$, considerando-se positivo a elevação de 4 vezes o título inicial.

Cultivos celulares. $O$ líquor e uma suspensão de fezes, tratados com fungicida e antibióticos, foram cultivados em celulas HEp-2 (câncer epidermóide de laringe humana) e RD (rabdomiosarcoma de embrião humano), sensíveis aos enterovírus de origem humana. As culturas foram incubadas a $37^{\circ} \mathrm{C}$ e observadas, diariamente, até o 9 dia, na busca de efeito citopático (ECP). As amostras positivas (presença de ECP) foram submetidas ao teste de neutralização com soros imunes para poliovirus (tipos 1, 2, e 3), fornecidos pelo $\mathrm{NIH}$ Research Reagent. As amostras não-pólio foram submetidas a novo teste de neutralização com uma mistura de soros que identifica a maioria dos enterovírus ("pool" de Lim e Benyesh-Melnick). Quando o isolamento de enterovírus ocorreu somente nas fezes e o teste PCR-EV foi negativo, o caso foi considerado como de provável etiologia viral.

Leptospirose. O diagnóstico de leptospirose pelo teste de micro-aglutinação ${ }^{5}$, foi realizado no Laboratório de Leptospira do CPqGM (FIOCRUZ, Salvador-Bahia). A bateria de cepas-padrão é composta por 26 sorovares, representantes de 18 sorogupos patogênicos e 2 não-patogênicos: Australis, Autumnalis, Ballum, Bataviae, Canicola, Celledoni, Cynopteri, Djasiman, Gripothyphosa, Hebdomadis, Icterohaemorrhagiae,
Javanica, Panama, Pomona, Pyrogenes, Serjoe, Shermani, Tarassovi, Andamana, e Semaranga. Os testes foram considerados positivos quando ocorreu aumento de título de quatro vezes, entre a $1^{\underline{a}}$ e a $2^{\text {a }}$ amostras séricas pareadas, ou um título recíproco superior a 800 em uma ou mais das amostras séricas e como caso provável se o título recíproco foi maior que 100 em uma ou mais das amostras séricas. As culturas de leptospiras foram mantidas em meio E.M.J.H líquido (Albumina-Tween 80), através de repiques semanais e no momento de uso eram diluídas em PBS $\mathrm{pH} 7,2^{5}$.

Apresentação clínica, exame do líquor diagnóstico e evolução. As características clínicas iniciais, liquóricas e os resultados dos testes diagnósticos foram registradas em questionário estruturado. Foram investigadas as variáveis: idade, sexo, febre, vômitos, convulsão, coriza e/ou tosse, diarréia, exantema, nível de consciência, sinais de irritação das meninges, celularidade, proteína e glicose do líquor, complicações e seqüelas imediatas.

Análise estatística. A análise estatística foi realizada pelo programa SPSS versão 6.1, utilizandose o teste do qui-quadrado na investigação das varáveis não-paramétricas e o teste "t" de Student para as variáveis paramétricas, sendo o intervalo de confiança (IC) de 95\%. Os resultados foram considerados significativos quando o valor da probabilidade (p) alfa (erro tipo I) foi $\leq 0,05$ (5\%).

\section{RESULTADOS}

Entre os 112 pacientes com SMA incluídos neste estudo, entre setembro de 1997 e março de 2000 (excluídos os períodos epidêmicos de leptospirose de abril a agosto de cada ano), o agente causal foi determinado em $44,6 \%(n=50)$ dos casos. Os enterovírus foram encontrados em 37,7 \% ( $n=42)$ dos casos, comprovado em $26,7 \%(n=30)$ e provável em $11,0 \%(n=12)$; enquanto, anticorpos antileptospira foram positivos em $7,1 \%(n=8)$ dos casos, sendo $5,3 \%(n=6)$ confirmados (4 do sorogrupo Icterohaemorrhagiae, um do Pomona e um do Pomona/ Hurstbridge) e 1,8 \% $(n=2)$ de casos prováveis (sorogrupo Pomona e Hurstbridge). Nenhum caso com anticorpos anti-arbovírus foi identificado pelo método sorológico da inibição da hemaglutinação.

A Tabela 1 mostra a freqüência de EV de acordo o espécime biológico, e o método diagnóstico utilizado. $\mathrm{O}$ teste Amplicor-EV (PCR) foi positivo em 30,7\% (28/91)

\begin{tabular}{|c|c|c|c|c|}
\hline Espécimes & & & \multirow{2}{*}{$\begin{array}{l}\text { Fezes } \\
\text { cultura }\end{array}$} & \multirow[b]{3}{*}{ Total } \\
\hline Métodos & PCR & cultura & & \\
\hline Resultados & \multicolumn{2}{|c|}{ n/total(\%) } & n /total (\%) & \\
\hline Positivo & $28 / 91(30,7)^{a}$ & $7 / 94(7,5)^{b}$ & $4 / 93(4,3)$ & $30 / 112(26,7)$ \\
\hline Provável & $-(-)$ & $-(-)$ & $12 / 93(12,9)^{c}$ & $12 / 93(12,9)$ \\
\hline Total & $28 / 91(30,7)$ & $7 / 94(7,5)$ & $16 / 93(17,2)$ & $42 / 112(37,5)$ \\
\hline
\end{tabular}

das amostras, mas os EV foram isolados por cultivo do líquor e das fezes, respectivamente, em 7,5\% (7/94) e $17,2 \%$ (16/93) dos casos. Em três pacientes observouse dois prováveis agentes causais: (1) paciente do sexo masculino de 12 anos com SMA por enterovírus, isolado no líquor, sorotipo não-identificado, cursou com manifestação clínica de exantema variceliforme a nível do tórax, característico de Herpes-zooster; (2) criança de 5 anos, do sexo feminino, com infecção por Leptospira sp (diagnosticada pela soro-conversão na 
micro-aglutinação) mais o PCR-EV também positivo; e (3) criança do sexo feminino, de 9 anos de idade, com diagnóstico de Leptospira sp. (soroconversão) foi isolado um EV não-identificado nas fezes (caso provável).

Entre os 22 enterovirus isolados, a partir de 23 cultivos ( 7 do líquor e 16 das fezes), foram identificados $14(63,6 \%)$ : três no líquor, 10 nas fezes e um simultâneamente no líquor e nas fezes. Na Tabela 2, observa-se que, entre os 14 identificados, foram encontrados seis diferentes sorotipos de enterovírus, sendo o Echovirus-4 o mais freqüente $(27,2 \%)$. Em uma criança de 3 meses, foi isolado nas fezes um enterovirus tipo pólio 2 (cepa vacinal), considerando o registro da $1^{\mathrm{a}}$ dose da vacina no cartão vacinal realizada 1 mês antes de desenvolver o quadro de SMA.

$\mathrm{Na}$ Tabela 3 é apresentada a correlação entre os resultados das culturas de fezes com os das culturas de líquor e os do PCR para enterovírus. Nos 16 casos em que cultura de fezes foi positiva para enterovírus, em quatro pacientes o teste PCR-EV foi positivo, sendo

Tabela 2 - Sorotipos de enterovírus identificados em casos de síndrome da meningite asséptica do Hospital Couto Maia (Salvador, Bahia) isolados de cultivos de líquor e de fezes.

\begin{tabular}{|c|c|c|c|c|}
\hline \multirow[b]{2}{*}{ Sorotipos } & \multicolumn{2}{|c|}{ Cultivos } & \multicolumn{2}{|c|}{ Total } \\
\hline & líquor & fezes ${ }^{(a)}$ & $\mathrm{n}^{\circ}$ & $\%$ \\
\hline Echovirus-4 (E-4) & 1 & 5 & 6 & 27,2 \\
\hline Echovírus-9 (E-9) & - & 1 & 1 & 4,5 \\
\hline Coxsackie-B2 (CB-2) & 2 & 2 & $3^{(\mathbf{b})}$ & 13,6 \\
\hline Coxsackie-B3 (CB-3) & 1 & 1 & 2 & 9,0 \\
\hline Coxsackie-B6 (CB-6) & - & 1 & 1 & 4,5 \\
\hline Enterovirus-71 (EV-71) & - & 1 & 1 & 4,5 \\
\hline Não identificado & 3 & 5 & 8 & 36,7 \\
\hline Total & 7 & 16 & 22 & \\
\hline
\end{tabular}

(a) isolado poliovírus tipo 2, cepa vacinal, em uma criança de 3 meses; (b) um de isolamento simultâneo no líquor e nas fezes.

Tabela 3 - Correlação dos resultados das culturas de fezes com os do líquor e do PCR para enterovírus de 93 crianças de Salvador-Bahia com síndrome de meningite asséptica.

\begin{tabular}{lcccccc}
\hline \multicolumn{7}{c}{ Tipos de resultados do exames do líquor ${ }^{\text {(a) }}$} \\
\hline Culturas(fezes) & n pacientes & cult $^{+}$e PCR & cult $^{+}$e PCR & cult e PCR & cult e PCR & Total \\
\cline { 2 - 7 } Positivos & 16 & - & 1 & 3 & 12 & 16 \\
Negativos & 77 & 2 & 2 & 15 & 58 & 77 \\
\hline Total & 93 & 2 & 3 & 18 & 70 & 93 \\
\hline
\end{tabular}

(a) Cult: cultura resultado positivo (+), resultado negativo (-)

que em um deles a cultura do líquor também foi positiva para Coxsackie B2 (Tabela 2). Em doze amostras de fezes positivas, as respectivas culturas do líquor e o PCR-EV foram negativas.

$\mathrm{Na}$ análise dos dados demográficos, das alterações do líquor e das manifestações clínicas iniciais, os 112 pacientes foram distribuídos entre os que tiveram (grupo 1) ou não (grupo 2) agente etiológico determinado. $A$ Tabela 4 mostra que não houve diferença estatística ( $p>0,05)$ entre as características demográficas e liquóricas entre os pacientes dos dois grupos. A ocorrência dos casos de SMA foi maior no sexo masculino $(61,7 \%)$ no grupo 1 e na faixa etária acima de 2 anos (81,5\%) no grupo 2, mas sem alcançar significância estatística. O número de células no líquor dos pacientes com SMA do grupo 1 foi em $29,8 \%$ (14/ 47) dos casos maior que $500 / \mathrm{mm}^{3}$, com limite superior de $1670 / \mathrm{mm}^{3}$, sendo o predomínio de neutrófilos em $23,4 \%$ $(11 / 47)$ dos casos. Em dois $(4,3 \%)$ casos houve aproximadamente igual proporção de neutrófilos e linfócitos.

Os sinais e sintomas, à admissão hospitalar, mais freqüentes foram descritos na Tabela 5 . Também não houve diferença estatística entre os dois grupos (1 e 2) de pacientes, porém o exantema foi mais freqüente no grupo 1, sem alcançar significância estatística ( $p>0,09)$. Três pacientes com o diagnóstico de SMA por enterovírus (grupo 1) e um do grupo 2 não foram internados, sendo acompanhados no ambulatório. Todos os pacientes evoluíram bem sem seqüelas clínicas imediatas, observados na alta e na revisão ambulatorial após 1 mês, ou em visita domiciliar até 2 meses da alta hospitalar.

\section{DISCUSSÃO}

As freqüências de $37,7 \%$ casos de SMA por enterovírus, e de 7,1\% por Leptospira sp. em período não-epidêmico em Salvador (Bahia, Brasil), foram semelhantes às referidas por outros estudos ${ }^{21} 22$. A freqüência de leptospirose $(7,1 \%)$ foi inferior a observada anteriormente (31\%) em 16 pacientes do HCMaia por Costa et al ${ }^{3}$. Em São Paulo, Romero et al ${ }^{17}$ encontraram $39,8 \%$ casos de portadores de DNA de 
Tabela 4 - Características demográficas e liquóricas dos pacientes com síndrome da meningite asséptica.

\begin{tabular}{|c|c|c|c|c|c|}
\hline \multirow[t]{2}{*}{ Variável } & \multicolumn{2}{|c|}{ Grupo 1} & \multicolumn{2}{|c|}{ Grupo 2} & \multirow[b]{2}{*}{$\mathrm{p}$} \\
\hline & $n^{0}$ & $\%$ & $\mathrm{n}^{0}$ & $\%$ & \\
\hline \multicolumn{6}{|l|}{ Sexo } \\
\hline masculino & 29 & 61,7 & 38 & 58,5 & 0,7 \\
\hline feminino & 18 & 38,3 & 27 & 41,5 & \\
\hline \multicolumn{6}{|l|}{ Idade (anos) } \\
\hline 3 meses $\dashv 2$ & 12 & 25,5 & 12 & 18,5 & \\
\hline $3 \mapsto 15$ & 35 & 74,5 & 53 & 81,5 & \\
\hline média $\pm d p$ & \multicolumn{2}{|c|}{$6,0 \pm 4,2$} & \multicolumn{2}{|c|}{$7,3 \pm 4,5$} & $0,3^{*}$ \\
\hline \multicolumn{6}{|l|}{ Liquor } \\
\hline \multicolumn{6}{|l|}{ células $/ \mathrm{mm}^{3}$} \\
\hline $10 \mapsto 500$ & 33 & 70,2 & 49 & 75,4 & 0,5 \\
\hline$\geq 501$ & 14 & 29,8 & 16 & 24,6 & \\
\hline limites $\left(\mathrm{mm}^{3}\right)$ & \multicolumn{2}{|c|}{10 e 1.670} & \multicolumn{2}{|c|}{22 e 1.300} & \\
\hline \multicolumn{6}{|l|}{ neutrófilos (\%) } \\
\hline$>50$ & 11 & 23,4 & 9 & 13,8 & 0,3 \\
\hline$<50$ & 34 & 72,3 & 56 & 86,2 & \\
\hline$\cong 50$ & 2 & 4,3 & 0 & & \\
\hline \multicolumn{6}{|l|}{ proteína (mg/dl) } \\
\hline $20 \mapsto 50$ & 37 & 78,7 & 51 & 78,5 & 0,9 \\
\hline $51 \dashv 150$ & 10 & 21,3 & 14 & 21,5 & \\
\hline \multicolumn{6}{|l|}{ glicose (mg/dl) } \\
\hline $40 \mapsto 50$ & 11 & 23,4 & 10 & 15,4 & 0,2 \\
\hline $51 \mapsto 65$ & 36 & 76,6 & 55 & 84,6 & \\
\hline
\end{tabular}

$\left({ }^{*}\right)$ teste t de Student

Tabela 5 - Manifestações clínicas mais freqüentes à admissão hospitalar dos pacientes com síndrome da meningite asséptica

\begin{tabular}{|c|c|c|c|c|c|c|c|}
\hline \multirow[b]{2}{*}{ Sinais e sintomas } & \multicolumn{3}{|c|}{ Grupo 1} & \multicolumn{3}{|c|}{ Grupo 2} & \multirow[b]{2}{*}{$p$} \\
\hline & $\mathrm{n}^{\circ}$ & total & $\%$ & $\mathrm{n}^{\circ}$ & total & $\%$ & \\
\hline Febre & 44 & 47 & 93,6 & 63 & 65 & 96,9 & 0,4 \\
\hline Cefaléia $^{a}$ & 28 & 31 & 90,3 & 46 & 48 & 95,8 & 0,3 \\
\hline Vômitos & 36 & 47 & 76,6 & 51 & 65 & 78,5 & 0,8 \\
\hline Convulsão & 3 & 47 & 6,4 & 5 & 65 & 7,7 & 0,7 \\
\hline Respiratórios & 3 & 47 & 6,4 & 10 & 65 & 15,4 & 0,1 \\
\hline Diarréia & 2 & 47 & 4,3 & 7 & 65 & 10,7 & 0,2 \\
\hline Exantema & 2 & 47 & 4,3 & 0 & 65 & - & 0,09 \\
\hline Sinais meningeos & 32 & 47 & 68,1 & 46 & 65 & 70,7 & 0,7 \\
\hline
\end{tabular}

a Somente entre os maiores de 4 anos de idade

leptospira pela PCR, no líquor de 108 pacientes, sem contudo afirmarem serem todos casos de SMA por este agente.

Sawyer et al ${ }^{18}$ estudaram um surto SMA por EV e separaram o líquor de sete pacientes em duas alíquotas, as cultivadas de imediato, logo após a coleta, foram todas positivas para EV enquanto apenas uma foi positiva entre as alíquotas estocadas a $-70^{\circ} \mathrm{C}$ e cultivadas 8 dias logo após a coleta. É possível que no presente estudo se a cultura do líquor fosse realizada de imediato, após a coleta, a positividade poderia ser maior. Por outro lado, a presença no líquor de inibidores da amplificação das partículas de enterovírus, fenômeno já descrito ${ }^{9}$, foi também observado neste estudo em dois pacientes, ambos com cultivos positivos do líquor e testes PCR-EV negativos.
Vliet et al ${ }^{25}$, em trabalho envolvendo oito centros de cinco países europeus, estudaram 184 pacientes de dois dias a 89 anos de idade e observaram o cultivo de EV no líquor de $13,6 \%$ (25/184) dos casos, sendo o PCR-Amplicor do líquor positivo em 24,5\% (45/184), ou seja, respectivamente superior aos 7,5\% (7/94) e inferior aos 30,7 \%, (28/91) observados na presente casuística. Enquanto os cultivos naquele trabalho ${ }^{25}$ foram realizados até 3 dias após a coleta do líquor, na presente investigação foi superior a 1 mês e isto talvez explique a diferença entre as freqüências observadas.

Entre os seis sorotipos identificados, apenas dois (CB3 e E9) foram também encontrados entre os 18 sorotipos do estudo de Vliet et a ${ }^{25}$. Por outro lado, exceto o CB6, todos os outros cinco (E4, E9, CB2, CB3 e EV71) estão entre os 15 sorotipos mais freqüentes encontrados 
nos Estados Unidos ${ }^{4}$. Vliet et a ${ }^{25}$ pesquisaram também EV em 94 pacientes com líquor normal, sem pleocitose e o cultivo foi positivo em 3,2\% e o PCR-EV em 7,4\% dos pacientes. Portanto, esta observação chama a atenção sobre a possibilidade de passar despercebido o diagnóstico de SMA, quando na fase inicial da infecção não há alteração liquórica.

Os cultivos de EV positivos, como em outros trabalhos ${ }^{71824}$, foram mais freqüente $(17,2 \%)$ nas fezes do que no líquor (7\%), embora somente 4 dos isolamentos nas fezes estavam associados à positividade no líquor (3 com PCR-EV e 1 com PCR-EV + cultura). Os outros 12 casos de EV, isolados nas fezes, têm forte possibilidade de serem os agentes etiológicos da SMA de acordo com a literatura ${ }^{7}$. Por sua vez, a identificação do EV-71 é preocupante, porque apresenta variantes de maior neurovirulência, como no grave surto ocorrido recentemente em Taiwan ${ }^{10}$, apesar de também ocorrer variantes associadas à doença de evolução benigna ${ }^{12}$.

A observação de possíveis formas de meningite mista na presente série de casos é referida também por outros estudos da SMA ${ }^{1326}$. No caso com EV nãoidentificado isolado no líquor mais Herpes-zooster (diagnóstico clínico), é possível que a infecção do SNC tenha ativado o vírus varicela-zooster, o qual também pode figurar como agente causal da SMA ${ }^{15}$.

As características do líquor dos pacientes com SMA por EV também foram observadas em outros estudos ${ }^{18,}$ ${ }^{24}$, inclusive a proporção de neutrófilos maior que $50 \%$ no líquor em aproximadamente em um quarto dos casos. $\mathrm{A}$ observação de celularidade no líquor acima $1000 / \mathrm{mm}^{3}$ em $6,4 \%$ (3/47) dos casos de SMA já foi também referida ${ }^{18}$, atingindo limites de até 4.000 células por milímetro cúbico ${ }^{24}$.

A evolução clínica dos pacientes sem complicações ou seqüelas clínicas, está de acordo com a maioria dos trabalhos sobre SMA de etiologia enteroviral ${ }^{361215}$. No entanto, a exclusão dos pacientes em coma (portadores de encefalite ou meningoencefalite), afastou provavelmente os portadores de formas graves raras de SMA, descritas na literatura ${ }^{14}$.

Em conclusão apesar de $55,4 \%$ dos casos sem diagnóstico etiológico, os enterovírus são os agentes etiológicos da SMA mais freqüentes em SalvadorBahia e que a leptospirose deve ser incluída no diagnóstico diferencial. Também as semelhanças entre os dois grupos de pacientes (com vs sem diagnóstico etiológico) também reforçam o diagnóstico presuntivo de SMA, de provável etiologia viral ou por leptospiras, para os pacientes do grupo 2 .

\section{REFERÊNCIAS BIBLIOGRÁFICAS}

1. Berlin LE, Rorabaugh ML, Heldrich F, Roberts K, Doran TI, Modlin JF. Aseptic meningitis in infants $<2$ years of age: diagnosis and etiology. Journal of Infectious Diseases 168: 888-892, 1993.

2. Clarke DH, Casals J. Techniques for hemagglutination and hemagglutination-inhibition with arthhropod-borne viruses. American Journal of Tropical Medicine and Hygiene 7: 561-577, 1958.

3. Costa E, Costa Y, Santos RR, Silva HR, Silva NG, Silva IC, Miranda Filho GV, Caldas EM, Sampaio EB. Leptospirose: uma causa de meningite asséptica. Revista Médica da Bahia 23:107108, 1977.

4. Enterovirus surveillance-United States, 1997-1999. Morbidity \& Mortality Weekly Report 49:913-916, 2000.

5. Faine S. Guidelines for control of leptospirosis. WHO, Geneva,1982.

6. Glimaker M, Ehrnst A, Magnius L, Berglund P, Forsgren M, Vilkerfors $T$, Olcén $P$. Early diagnosis of enteroviral meningitis by a solid- phase reverse immunosorbent test and virus isolation. Scandinavian Journal of Infectious Diseases 22:519-526, 1990.

7. Glimaker $M$, Abebe A, Johansson B, Ehrnst A, Olcén P, Strannegard O. Detection of enteroviral RNA by polymerase chain reaction in faecal samples from patients with aseptic meningitis. Journal of Medical Virology 38:54-61, 1992.

8. Glimaker M, Johansson B, Olcén P, Ehrnst A, Forsgren M. Detection of enteroviral RNA by polymerase chain reaction in cerebrospinal fluid from patients with aseptic meningitis. Scandinavian Journal of Infectious Diseases 25: 547-557, 1993.

9. Hadziyannis E, Cornish N, Starkey C, Procop GW, Yen-Lieberman B. Amplicor enterovirus polymerase chain reaction in patients with aseptic meningitis. A sensitive test limited by amplification inhibitors. Archives of Pathology \& Laboratory Medicine 123: 882884, 1999.
10. Ho M, Chen ER, Hsu KH, Twu SJ, Chen KT, Tsai SF, Wang JR, Shih SR. An epidemic of enterovirus 71 infection in Taiwan. New England Journal of Medicine 341:929-935, 1999.

11. Lopes OS, Coimbra TLM, Sacchetta LA, Calisher CH. Emergence of a new arbovirus disease in Brazil. Isolation and characterization of the etiologic agent, rocio virus. American Journal of Epidemiology 107:444-449, 1978.

12. Merovitz BSCL, Demers AM, Newby, DMD, McDonald JMD. The enterovirus 71 infections at Canadian center. Pediatric Infectious Disease Journal 19:755-757, 2000.

13. Meyer HM, Johnson RT, Crawford IP, Dascomb HE, Rogers NG. Central nervous system syndromes of "viral" etiology. A study of 713 cases. American Journal of Medicine 29:334-347,1960.

14. Modlin JF, Dagan R, Berlin, LE, Virshup DM, Yolken RH, Menegus $M$. Focal encephalitis with enterovirus infections. Pediatrics 88:841-845, 1991.

15. Nelsen S, Sealy DP, Schneider EF. The aseptic meningitis syndrome. American Family Physician 48:809-815, 1993.

16. Pinheiro FP, Rocha AG, Freitas RB, Ohana BA, Travassos da Rosa APA, Rogério JS, Linhres SAC. Meningite associada as infecções por vírus Orepouchel. Revista do Instituto de Medicina de São Paulo 24:246-251, 1982.

17. Romero EC, Billerbeck AE, Lando VS, Camargo ED, Souza CC, Yasuda PH. Detection of leptospira DNA in patients with aseptic meningitis by PCR. Journal Clinical Microbiology 36:1453-1455, 1998.

18. Sawyer MH, Holland D, Aintablian N, Connor JD, Keyser EF, Waecker Jr NJ. Diagnosis of enteroviral central nervous system infection by polymerase chain reaction during a large community outbreak. Pediatric Infectious Disease Journal 13:177-182, 1994.

19. Shope RE. The use of a microhemagglutination-inhibition test to follow antibody response after artrhopod-borne virus infection in 
community of forest animals. Annals Microbiology 11 (part A): 167-177, 1963.

20. Silva RJM, Carvalho AP, Guedert JM, Silva MRC. Meningite asséptica: análise de um surto epidêmico. Arquivo Catarinense de Medicina 14:17-22, 1985.

21. Sperber SJ, Schleupner CJ. Leptospirosis: a forgotten cause of aseptic meningitis and multisystem febrile illness. Southern Medical Journal 82:1285-1287, 1987.

22. Suárez M, Pelegrino J, Más P. Caracterización etiológica de meningoencefalitis. aséptica en la provincia Ciego de Avila. In: Resumo do V Congresso Latinoamericano de Medicina Tropical, Havana, p.165, 1997.

23. Takimoto S, Tanaka H, Gomes LFS, Waldmen EA, Pereira HG, Paiva TM, Coimbra TL, Ueda M, Meles HHG. Preliminary characterization of a new virus isolated from the spinal fluid of patients with meningitis in São Paulo, Brazil. Revista do Instituto de Medicina Tropical de São Paulo 32: 162-167, 1990.

24. Thorén A, Widell A. PCR for the diagnosis of enteroviral meningitis. Scandinavian Journal of Infectious Diseases 26:249-254, 1994.

25. Vliet KE van, Glimaker M. Lebon P, Klapler PE, Taylor CE, Ciardi M, Avoort MM van der, Diepersloot RJA, Kurtz J, Peeters MF, Cleator GM, Loon AM van. Multicenter evaluation of the Amplicor enterovirus PCR test with cerebrospinal fluid from patients with aseptic meningitis. Journal of Clinical Microbiology 36:2652-2657, 1998.

26. Wright HT, McAllister RM, Ward R. "Mixed" meningitis. Report of a case with isolation of Haemophilus influenzae type $B$ and $\mathrm{ECHO}$ virus type 9 from the cerebrospinal fluid. New England Journal of Medicine 267:142-144, 1962. 